\title{
Sosialisasi Tangguh Bencana Banjir Di Desa Sungai Tabuk, Kecamatan Simpang Empat, Kabupaten Banjar, Provinsi Kalimantan Selatan
}

\author{
Andi Tenri Sompa ${ }^{1}$, Yuanita Setyastuti ${ }^{2}$, Yayan Daryanto ${ }^{3}$, Akhmad Piqi Adum Damara ${ }^{4}$, I Gede Kariada ${ }^{5}$, \\ Ilhamuddin ${ }^{6}$, Lisa Yuliana ${ }^{7}$, Maira Ulfah ${ }^{8}$, Raudatul Jannah', Ratih Andriani ${ }^{10}$ \\ ${ }^{1,2}$ Universitas Lambung Mangkurat, Fakultas Ilmu Sosial dan Ilmu Politik, \\ Jl. H. Hassan Basry Banjarmasin, Indonesia, \\ ${ }^{3}$ Badan Penanggulangan Bencana Daerah Kabupaten Banjar, South Kalimantan Selatan, Indonesia, \\ ${ }_{4,5,6,7,8,9,10}$ Mahasiswa Program Studi Ilmu Pemerintahan, Universitas Lambung Mangkurat, Fakultas Ilmu \\ Sosial dan Ilmu Politik, \\ Jl. H. Hassan Basry, Banjarmasin, Indonesia, \\ *email korespondensi: tenri@ulm.ac.id
}

Diajukan 29 Oktober 2021

\section{Informasi Artikel}

Diterima

20 November 2021
Diterbitkan

30 November 2021

\section{Keywords:}

Sosialisasi Tangguh Bencana Upaya pencegahan banjir Pemulihan pascabanjir Desa Sungai Tabuk

\begin{abstract}
At the beginning of the year, high rainfall triggered overflows of river water which, in flooding, one of which was in Sungai Tabuk Village, Simpang Empat District, Banjar Regency. The purpose of this service is to provide knowledge about potential disasters, characteristics, impacts, and cycles of flood disaster management for the village government and the people of Sungai Tabuk Village. The methodology used to provide understanding and increase awareness and improve communication between communities is through the Socialization of Flood Disaster Resilient. From this activity, it will increase public understanding and awareness to know the threat of disasters in their area so that they are able to organize and reduce disaster risk to reduce vulnerability to disasters with preparedness and make efforts to prevent and recover post-floods.
\end{abstract}

\section{ABSTRAK}

Di awal tahun curah hujan yang tinggi memicu terjadinya luapan air sungai, sehingga mengakibatkan banjir, salah satunya di Desa Sungai Tabuk, Kecamatan Simpang Empat, Kabupaten Banjar. Tujuan Pengabdian adalah untuk memberikan pengetahuan tentang potensi bencana, karakteristik, dampak, dan siklus penanggulangan bencana banjir bagi pemerintah desa dan masyarakat Desa Sungai Tabuk. Metodologi yang digunakan untuk memberikan pemahaman dan meningkatkan kesadaran dan memeperbaiki komunikasi antar masyarakat ini melalui Sosialisasi Tangguh Bencana Banjir. Hasil yang diperoleh dalam kegiatan ini, di harapkan meningkatkan pemahaman dan kesadaran masyarakat dalam menghadapi ancaman bencana di wilayahnya, sehingga mampu mengorganisir dan mengurangi risiko bencana untuk mengurangi kerentanan terjadinya bencana dengan kesiapsiagaan serta melakukan upaya-upaya pencegahan dan pemulihan pascabanjir.

\section{Copyright and License:}

Authors retain copyright and grant the journal right of first publication with the work simultaneously licensed under a Creative Commons Attribution 4.0 International License that allows others to share the work with an acknowledgment of the work's authorship and initial publication in this journal.

Journal homepage: $\underline{\text { tttps://ojs.wiindonesia.com/index.php/jecsr }}$ 


\section{PENDAHULUAN}

Bencana Alam merupakan peristiwa alam yang bisa bersifat tunggal atau bisa lebih dari satu peristiwa yang terjadi dalam waktu hampir bersamaan. Contoh bencana alam yang bersifat tunggal adalah bencana gunung meletus, angin puting beliung, dan banjir. Terjadinya bencana alam tidak dapat diprediksi, tetapi masyarakat mampu mengurangi resiko yang ditimbulkan oleh bencana tersebut. Untuk mengurangi resiko bencana, masyarakat perlu mengetahui jenis dan karakteristik bencana tersebut.

Bencana Banjir merupakan sebuah permasalahan dalam proses pembangunan Indonesia saat ini. Fenomena bencana banjir merupakan fenomena saling terkait antara variabel sosial, alam dan lingkungan. Beberapa literatur menyebutkan banjir disebabkan oleh curah hujan, tanah longsor, kualitas saluran air, topografi, dan kualitas daerah aliran sungai (DAS). Faktor lain yang tidak kalah pentingnya dalam menyumbang tragedi banjir di tanah air adalah perilaku atau budaya masyarakat yang kurang kondusif yang tercermin dari aktivitas ekonomi, sosial, politik dan seni serta aktivitas berlalulintas, baik di jalan raya maupun di air, yang semuanya itu terkait dengan masalah pentingnya pendidikan lingkungan hidup.Bencana banjir sangat merugikan masyarakat, seperti kerugian harta benda, korban jiwa, dan kerusakan lingkungan. Pengetahuan, pemahaman, dan keterampilan kesiapsiagaan dalam mencegah, mendeteksi, dan mengantisipasi secara lebih dini tentang dampak banjir diperlukan untuk meminimalisasi dampak yang ditimbulkan oleh banjir (Handayani et al., 2019).

Desa Tangguh Bencana merupakan suatu desa yang memiliki kemampuan untuk mengenali ancaman di wilayahnya dan mampu mengorganisir sumber daya masyarakat untuk mengurangi kerentanan dan sekaligus meningkatkan kapasitas demi mengurangi risiko bencana. Kemampuan ini diwujudkan dalam perencanaan pembangunan yang mengandung upaya-upaya pencegahan, kesiapsiagaan, pengurangan risiko bencana dan peningkatan kapasitas untuk pemulihan pascabencana (Munita, 2015).

Kegiatan Sosialisasi Tanggap Bencana dilaksanakan di Desa Sungai Tabuk, Kecamatan Simpang Empat, Kabupaten Banjar. Target pengabdian ini adalah perangkat desa dan masyarakat untuk kesiapsiagaan bencana karena wilayah tersebut rentan banjir sehingga perlu menjadi prioritas dalam mengetahui potensi bencana, karakteristik bencana banjir, dampak bencana, penanganan bencana dan siklus penanggulangan bencana bagi pemerintah desa dan masyarakat Desa Sungai Tabuk. Bencana alam seperti banjir yang terjadi pada awal tahun merupakan hal pertama yang terburuk terjadi di kabupaten Banjar, kurangnya pengetahuan serta kurangnya komunikasi antar masyarakat dengan Badan Penanggulangan Bencana Daerah (BPBD) dalam mitigasi bencana banjir membuat dampak yang dirasakan oleh desa maupun masyarakat semakin buruk. Seperti yang terjadi pada Desa Sungai Tabuk, Kecamatan Simpang Empat, Kabupaten Banjar, kurangnya pengetahuan dan komunikasi antar masyarakat dengan Badan Penanggulangan Bencana Daerah (BPBD) membuat evakuasi yang dilakukan saat itu terlambat, keadaan banjir saat itu sudah tinggi hingga membuat kantor serta rumah masyarakat desa terendam oleh banjir.

Berdasarkan latar belakang diatas, maka sangat diperlukan pemahaman yang tepat kepada masyarakat terhadap bencana banjir agar mereka bisa mengantisipasi serta meminimalisir adanya korban jiwa dan kerugian materi. Melihat hal tersebut maka sangat diperlukan adanya pengabdian dengan judul "Sosialisasi Tangguh Bencana Banjir di Desa Sungai Tabuk, Kecamatan Simpang Empat, Kabupaten Banjar. Setelah mendapatkan sosialisasi ini hendaknya masyarakat bisa memahami dan menjadi bekal sendiri untuk mengetahui bagaimana cara menanggulangi bencana banjir dengan baik tanpa adanya hambatan.

\section{METODE}

Sosialisasi menurut Charles R Wright yang dikutip oleh Sutaryo adalah "Proses ketika individu mendapatkan kebudayaan kelompoknya dan menginternalisasikan sampai tingkat tertentu norma-norma sosialnya, sehingga membimbing orang tersebut untuk memperhitungkan harapan-harapan orang lain". Sosialisasi merupakan suatu proses bagaimana memperkenalkan sebuah sistem pada seseorang dan bagaimana orang tersebut menentukan tanggapan serta reaksinya. Sosialisasi ditentukan oleh lingkungan sosial, ekonomi dan kebudayaan dimana individu berada, selain itu juga ditentukan oleh interaksi pengalaman-pengalaman serta kepribadiannya. Sosialisasi adalah suatu proses sosial yang terjadi bila seorang individu mendapatkan pembentukan sikap untuk berperilaku yang sesuai dengan perilaku kelompok sosialnya. Teknik pengumpulan data yang dilakukan yaitu pengumpulan data dengan melakukan survei kondisi dan keadaan Desa dan referensi dari pustaka dengan strategi kegiatan dengan memberikan meteri dalam kegiatan, menyajikan sosialisasi/praktik secara langsung adanya monitoring dan evaluasi. 
Metodologi yang digunakan untuk melakukan sosialisasi ini dengan melakukan survei permasalahan mengenai bencana yang terjadi di desa kemudian dilanjutkan dengan mengajak perangkat desa dan masyarakat untuk ikut berpartisipasi dalam kegiatan sosialisasi,dengan hasil adanya izin dari Kepala Desa dan kesepakatan untuk pelaksanaan kegiatan ini,selanjutnya adalah menjalankan tahap berikutnya yaitu, mengakses informasi, menyiapkan bahan materi pembahasan yang akan disampaikan dan peralatan penunjang kegiatan Sosialisasi. Kegiatan ini dilaksanakan dengan rancangan penyampaian materi Tangguh Bencana Banjir kemudian lanjutkan dengan sesi tanya jawab kepada peserta Sosialisasi yaitu Perangkat Desa dan Masyarakat Desa Sungai Tabuk, Kecamatan Simpang Empat, Kabupaten Banjar Provinsi Kalimantan Selatan. Pelaksanaanya berlangsung selama 2 jam pada Tanggal 30 Agustus 2021 secara Hybrid. Evaluasi yang dilakukan adalah menyampaikan aspirasi dan keluh kesah masyarakat dengan pihak Badan Penanggulangan Bencana Daerah terkait bencana banjir.

Melalui sosialisasi tangguh bencana banjir dapat memberikan pengetahuan dan pembelajaran mengenai potensi bencana, karakteristik bencana banjir, dampak bencana, penanganan bencana dan siklus penanggulangan bencana bagi pemerintah desa dan masyarakat Desa Sungai Tabuk dikarenakan daerah tersebut sangat rawan akan bencana banjir yang hampir setiap tahunnya terjadi, sebagai manusia tidak dapat memprediksi kapan akan terjadi bencana. Bencana bisa di kelola sehingga dampaknya dapat dikendalikan. Dan setelah mendapatkan sosialisasi ini hendaknya masyarakat bisa memahami dan menjadi bekal sendiri untuk mengetahui bagaimana cara menanggulangi bencana banjir dengan baik tanpa adanya hambatan. Dari kondisi alam Indonesia yang memang rawan kebencanaan, maka sebagai manusia kita harus sadar bahwa hidup dalam wilayah rawan bencana. Untuk itu perlu menanamkan pemahaman dan pembelajaran melalui pendidikan formal maupun non formal, sosialisasi ke masyarakat untuk menambah wawasan pengetahuan di bidang bencana sehingga diharapkan masyarakat dapat berkontribusi secara pro aktif.

\section{HASIL DAN PEMBAHASAN}

Dari kondisi Desa Sungai Tabuk yang memang rawan bencana banjir saat terjadinya curah hujan yang tinggi di saat musim penghujan.Untuk itu dalam pengabdian ini dilakukan"Sosialisasi Tangguh Bencana Banjir di Desa Sungai Tabuk, Kecamatan Simpang Empat, Kabupaten Banjar, Provinsi Kalimantan Selatan". Sosialisasi dilakukan pada Perangkat Desa dan Masyarakat. Sosialisasi Tangguh Bencana ini dilakukan untuk memberikan pengetahuan dan pembelajaran mengenai potensi bencana, karakteristik bencana banjir, dampak bencana, penanganan bencana dan siklus penanggulangan bencana bagi pemerintah desa dan masyarakat Desa Sungai Tabuk dikarenakan daerah tersebut sangat rawan akan bencana banjir yang hampir setiap tahunnya terjadi. Sehingga perlunya mengetahui bagaimana cara menanggulangi bencana banjir dengan baik tanpa adanya hambatan. Tahapan yang dilakukan pada kegiatan pengabdian sebagai berikut :

\subsection{Tahapan Persiapan}

Tahap persiapan untuk melakukan Sosialisasi Tangguh Bencana Banjir di Desa Sungai Tabuk Kecamatan Simpang Empat Kabupaten Banjar dimulai dari mengurus perizinan kepada Kepala Desa, menentukan tanggal pelaksanaan sosialisasi, serta menghimbau perangkat desa dan masyarakat untuk ikut berpartisipasi dalam pelaksanaan kegiatan sosialisasi. Tahap berikutnya, menyiapkan bahan materi pembahasan yang akan disampaikan mengenai bahaya dan cara penanggulangan banjir yang meliputi potensi banjir, karakteristik bencana banjir, dan dampak yang timbul saat terjadinya banjir, dan siklus penanggulangannya serta tempat dan peralatan penunjang kegiatan seperti: Laptop, Handphone. Kegiatan ini dilakukan secara online melalui aplikasi Zoom Application.

\subsection{Tahapan Pelaksanaan Sosialisasi Online}

Tahapan pelaksanaan sosialisasi tangguh bencana banjir ini dilaksanakan pada Tanggal 30 Agustus 2021 pukul 10.00-12.00 WITA yang berlangsung di SMPN3 Simpang Empat secara online dimana para peserta sosialisasi yaitu Kepala Desa beserta perangkat desa, Badan Permusyawaratan Desa (BPD), Pembinaan Kesejahteraan Keluarga (PKK) dan Masyarakat Desa sosialisasi ini dilaksanakan dengan menggunakan Aplikasi Zoom, dimulai dengan sambutan dari Kepala Desa Sungai Tabuk, Dosen Pembimbing Lapangan dan Ketua Pelaksana Pengabdian. kemudian penyampaian materi tangguh bencana banjir mengenai potensi bencana, karakteristik bencana banjir, dampak bencana, dan siklus penanggulangan bencana. Setelah mendapatkan sosialisasi ini hendaknya masyarakat bisa memahami cara menanggulangi bencana banjir dengan baik tanpa adanya hambatan, kemudian dilanjutkan dengan sesi tanya jawab oleh peserta sosialisasi kepada Badan Penanggulangan Bencana Daerah sebagai pemateri.

Journal Empowerment and Community Service Vol. 1, No. o1, November 2021 


\subsection{Tahapan Ketercapaian Sasaran}

Setelah pelaksanaan kegiatan pengabdian berupa Sosialisasi Tangguh Bencana Banjir di Desa Sungai Tabuk Kecamatan Simpang Empat Kabupaten Banjar mencapai target sasaran masyarakat jadi lebih mengetahui bahaya dan penanggulangan bencana banjir. Sehingga masyarakat dan Badan Penanggulangan Bencana Daerah (BPBD) bisa saling menyelesaikan permasalahan banjir.

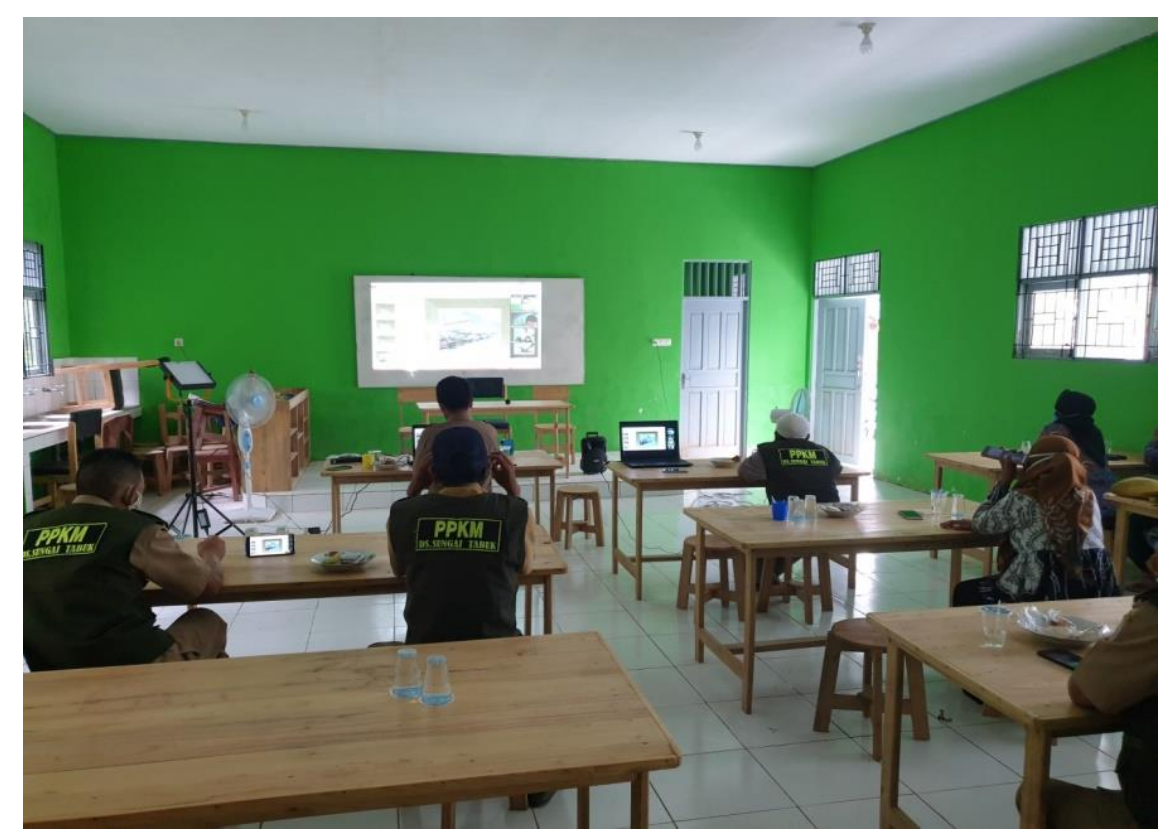

Gambar 1 Dokumentasi Pelaksanaan Sosialisasi Tangguh Bencana Banjir di SMPN 3 Simpang Empat Desa Sungai Tabuk Bersama Perangkat Desa dan Masyarakat Setempat secara online

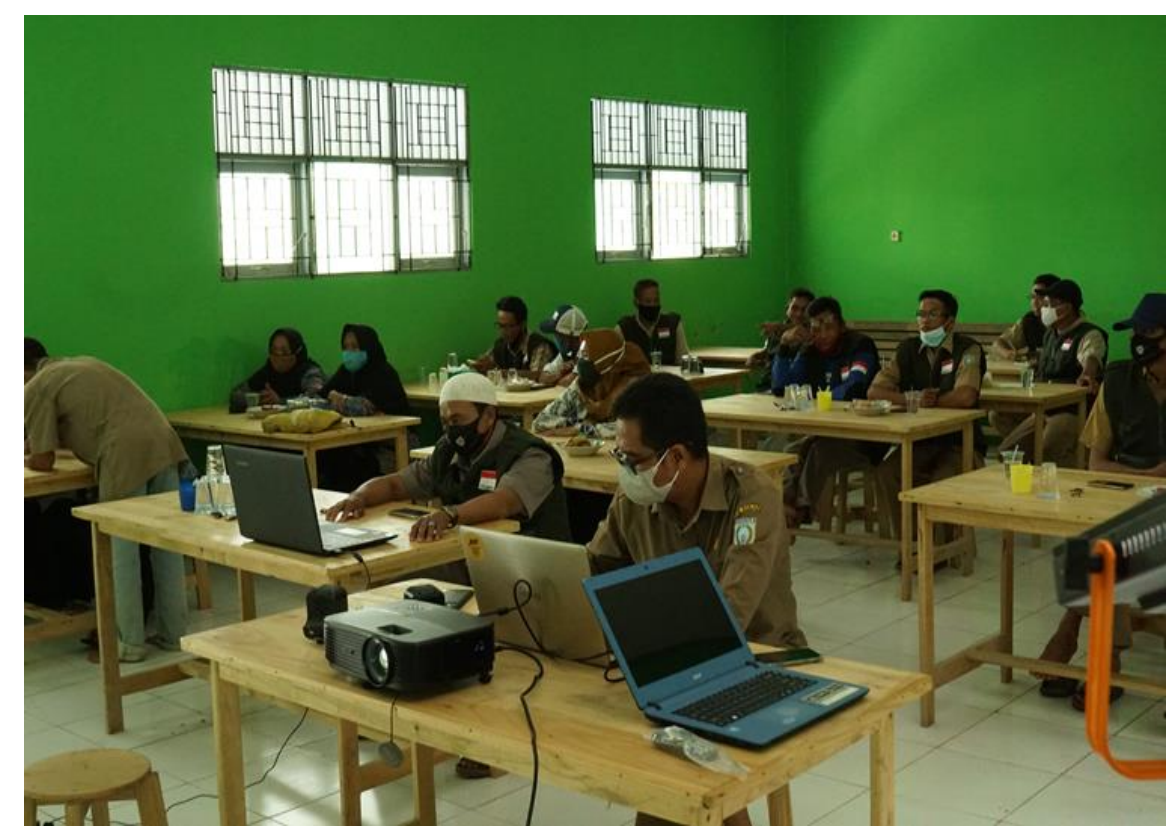

Journal Empowerment and Community Service Vol. 1, No. o1, November 2021 


\section{KESIMPULAN}

1) Bencana banjir sering terjadi di daerah Kabupaten Banjar salah satunya Desa Sungai Tabuk setiap tahun yang diakibatkan karena intensitas curah hujan yang tinggi menyebabkan meluapnya aliran sungai sehingga memicu terjadinya banjir. Bencana banjir sangat merugikan masyarakat, seperti kerugian harta benda, korban jiwa, dan kerusakan lingkungan. Pengetahuan, pemahaman, dan keterampilan kesiapsiagaan dalam mencegah, mendeteksi, dan mengantisipasi secara lebih dini tentang dampak banjir diperlukan untuk meminimalisasi dampak yang ditimbulkan oleh banjir.

2) Target pengabdian ini adalah perangkat desa dan masyarakat untuk kesiapsiagaan bencana karena wilayah tersebut rentan banjir sehingga perlu menjadi prioritas dalam mengetahui potensi bencana, karakteristik bencana banjir, dampak bencana, dan siklus penanggulangan bencana bagi pemerintah desa dan masyarakat Desa Sungai Tabuk. Bencana alam seperti banjir yang terjadi pada awal tahun 2021 merupakan hal pertama yang terburuk terjadi di kabupaten Banjar.

3) Sangat diperlukan pemahaman yang tepat kepada masyarakat terhadap bencana banjir agar mereka bisa mengantisipasi serta meminimalisir adanya korban jiwa dan kerugian materi. Oleh karena itu dilaksanakan kegiatan Sosialisasi Tangguh Bencana Banjir Di Desa Sungai Tabuk. Sehingga kegiatan sosialisasi ini bisa membuat masyarakat mengentahui bahaya dan cara penanggulangan bencana banjir. Sehingga masyarakat dan Badan Penanggulangan Bencana Daerah (BPBD) komunikasinya berjalan dengan baik agar bisa mnyelesaikan permasalahan banjir secara bersama-sama.

\section{UCAPAN TERIMA KASIH}

Ucapan terima kasih disampaikan kepada FIIP Universitas Lambung Mangkurat dan Pemerintah terkait yang telah mendukung berlangsungnya kegiatan ini.

\section{REFERENSI}

Rohmat. (2019). Penanggulangan Bencana Alam Klimatologis. Jakarta: Duta Penerbit.

Sutaryo. (2004). Dasar-Dasar Sosialisasi. Jakarta: Rajawali Press.

Ulfi Andrian Sari, H. L. (2021). Sosialisasi Mitigasi Bencana Banjir Melalui Pendidikan Kebencanaan berbasis Kearifan Lokal.

Muslimin. (2018). Ssosialisasi Tanggap Bencana Pada Masyarakat di Kec.Lemito, Kab.Pohuwato untuk Mewujudkan Desa Tangguh Bencana melalui Pendekatan Komunikasi Efektif dengan Bahasa yang Santun.

fahrudin, A. (2021). Sosilisasi Tanggap Bencana melalui Alat Peraga Edukasi SDN Keboireng Kecamatan Besuki, kabupaten Tulungagung.

Koodotie, R. d. (2002). Banjir: Beberapa penyebab dan metode pengendaliannya dalam perspektif lingkungan. Yogyakarta: Pustaka Pelajar. 